\title{
Current state of non-destructive testing and evaluation
}

\section{Editorial}

Non-destructive testing is widely used in the engineering industry to evaluate the condition of materials, objects and structures subjected to loading. The loading conditions vary from normal, cyclic to longterm. In this regards much research is being conducted around the world to develop more reliable tools and methods that can give engineers a certain estimate about the performance capabilities of the engineering structures. Much of the developed world i.e. North America and Europe are finishing the post-war development and are entering the phase of durability and sustainability. On the other end of spectrum majority of the developing countries in the Middle East and Asia is under-going a boom in construction. In this regards the need to develop reliable non-destructive testing technology and methods is heightened. There are two main approaches to solving this engineering problem. First being too start of fresh and develop new ideas into working prototypes and test their application and use in real-world situ-actions. Such an approach is useful for developing NDT techniques for 3D printed objects, however the demerit of such an approach is that it can be time consuming and require much trial and error, in addition the lacking of reliable data bank of knowledge also adds to the speculations related to the reliability of judgments based on these techniques. The second approach is to use existing NDT technology and to modify it for using in newly development ways. The benefit of this approach is that using the existing NDT technology adds to the inherent reliability of tools and the newly development modification or method of use brings confidence in realworld application..$^{1,2}$

Using the second approach of modifying existing NDT technology to perform new functions, Saleem et al. ${ }^{1,2}$ recently developed an innovative use of Rebound Schmidt Hammer by using the rebound number considering its corresponding energy imparted during each rebound to estimate the pull-out load carrying capacity of steel anchor bolts in a non-destructive manner. This approach has received much acknowledgement in the recent past as it not only allows engineers to non-destructively estimate the pull-out strength but is also backed by the reliability of traditional Schmidt Hammer technique. Additional benefit of the proposed technique is that the Schmidt Hammer Rebound number can also be used to estimate the defects in anchor bolt installation, such as ill-alignment, presence of air voids and internal cracking. The inventors recently also developed an innovative
Volume 3 Issue 7 - 2017

\author{
Muhammad Saleem \\ Department of Basic Engineering College, University of \\ Dammam, Saudi Arabia
}

Correspondence: Muhammad Saleem, Department of Basic Engineering College, University of Dammam, Saudi Arabia, Email mssharif@uod.edu.sa

Received: July 07, 2017 | Published: December 29, 2017

new use of Ultrasonic Pulse Velocity Test to estimate the degradation in bond of steel reinforcement embedded in concrete. The future goal of the team is to refine both the presented techniques and to generate a vault of reliable data for use in commercial applications. The innovations suggested by the author can add a new dimension to the use of existing non-destructive testing technology and can bring about a change in the way engineers use these tools. The objective of the author is to shed light on the global demand of NDT technology and highlight the direction in which the industry is heading in the coming future. It will be immense please to the author if the essay serves as guideline to the fellow researchers, engineers and students. ${ }^{3}$

\section{Acknowledgments}

No acknowledgement.

\section{Conflicts of interest}

No conflict of interest.

\section{References}

1. Saleem M, Walid A, Nabil A, et al. Non-destructive testing method to evaluate the load carrying capacity of concrete anchors. ASCE Journal of Construct Engineering and Management. 2016;142(5):1-8.

2. Saleem M, Nasir M. Bond evaluation of steel bolts for concrete subjected to impact loading. RILEM Materials and Structures. 2016;49(9):3635-3646.

3. Saleem M. Study to Detect Bond Degradation in Reinforced Concrete Beams Using Ultra-sonic Pulse Velocity Test Method. Structural Engineering and Mechanics. 2017. 